\title{
Value of American Higher Education: Non-Parametric Analysis of a LinkedIn Survey
}

\author{
Robb Elton \\ School of Business, Northcentral University, La Jolla, CA, USA \\ Email: r.elton3368@o365.ncu.edu
}

How to cite this paper: Elton, R. (2021). Value of American Higher Education: NonParametric Analysis of a LinkedIn Survey. Creative Education, 12, 2869-2880. https://doi.org/10.4236/ce.2021.1212214

Received: November 17, 2021 Accepted: December 24, 2021

Published: December 27, 2021

Copyright (c) 2021 by author(s) and Scientific Research Publishing Inc. This work is licensed under the Creative Commons Attribution International License (CC BY 4.0).

http://creativecommons.org/licenses/by/4.0/ (c) (i) Open Access

\begin{abstract}
The costs of a higher education are preclusive for many Americans. This is true despite the trend over the years for legal policy to encourage greater access for underrepresented demographics. This paper reports on the freeeducation trend via inquiry of a variety of professionals, students, and academics via LinkedIn $(n=621)$. After conducting a series of Wilcoxon SignedRank tests on the survey data, the results indicated that higher education holds definite perceptual value, while also suggesting concerns in terms of cost. The true cost of some higher education versus its practical, financial, future-value remains an issue to be balanced by society. This debate will also need to implicate access to education by poor and minority demographics. There is a definable need for further studies comparing policy options; whether they are derived from social media or a conference room is less important than if we fail to have these discourses at all.
\end{abstract}

\section{Keywords}

Higher Education, Hypothesis Testing, Non-Parametric Analysis, Likert Scales, Qualitative Research, Wilcoxon Signed-Rank, Survey, Grounded Theory

\section{Introduction}

Higher education attendance, until the mid-twentieth century, was historically monopolized by the wealthy white male in the United States (Cabrera, Franklin, $\&$ Watson, 2016: p. 8). Women have also been specifically excluded from higher education, a policy that stemmed from the colonial period (Ornstein, 2019: p. 336). Interestingly, these two phenomena have also been reported in contemporary British academia (Woolston, 2020). Higher education in the United Statesindeed all levels of schooling-remained racially segregated until major Supreme 
Court cases resulting from the civil rights movements culminated in changes in the 1950s and 1960s (e.g., Brown v. Board of Education of Topeka, 1954) ${ }^{1}$. Today, while de jure discrimination is not legally permitted, certain challenges yet exist for the less-fortunate and working demographic, that is, as applied to nonwhites, non-binary white-males. The policy of "redistricting" landscapes also further results in de facto segregation, and is currently permissible (see Milliken v. Bradley, 1974)2 ${ }^{2}$. Work needs to be done to create a more fair educational structure in America.

Recent research has discovered that for all its advantages, mass higher education has had no measurable effect on the rate of social mobility or "liberation" into the next socioeconomic class for non-whites (Jencks, Riesman, \& Jencks, 2002). Similarly, the extent that a degree influences equality in American society was reported about two decades ago by Jencks et al. (2002) and recently by Ornstein (2019). Not much has changed in two decades. Moreover, higher education for non-whites is farther from a guarantee of success later. Though, as the United States turns more heterogeneously brownish, problems also emerge for the poorer citizens who represent any color. Only a few years ago, a median $46 \%$ of college and community college students were food insecure, housing insecure, or homeless (Goldrick-Rab, Richardson, Schneider, Hernandez, \& Cady, 2018). Similar data was also reported by the Lumina Foundation (2021). There is a clear problem.

The median age of all level college students is 28.5-year of age (Vuleta, 2021). Additionally, older students from less-affluent socioeconomic situation tend to be parents, and have full-time employment in addition to attending college. The median income for this demographic is $\$ 13,880$ per year (Urban Institute, 2021). Combined with unfavorable university costs, unfriendly federal policies, and in not having abundant wealth, this student population must resort to borrowing money. It might not be so surprising then that student loan debt in the US totals over \$1.67 trillion (Hornsby, 2021). The act of taking out loans for a higher education, will often later, exacerbate their financial situations. Sometimes these unpaid student loans contribute to diminished credit, poor credit, even bankruptcy for debts other than student loan debt (e.g., mortgage, car, credit card). Moreover, credit is connected to nearly every major life purchase or lease. Ultimately, we are left with a poorer ex-college student and struggling college graduate.

\section{Purpose}

These national problems led the author to wonder about perceptions and opinions related to accessing higher education. What do the educated of America think? The author then looked into select social media platforms as source material, as these platforms have become a vast medium from which to obtain rapid, often immediate feedback regarding opinions and likes. The purpose in this ${ }^{1}$ Brown v. Board of Education of Topeka, 347 US 483 (1954)

${ }^{2}$ Milliken v. Bradley, 418 US 717 (1974). 
study was to discover what an educated, select community thought about specific educational ideas. To accomplish this a survey was designed.

\section{Rationale}

Social media plays a large part in entrepreneurship and wealth creation, to include Twitter, Facebook/Meta, YouTube, and WordPress, for example. However, other than YouTube-which is specific to content creators-none of the other social media have users congested in a platform with others who are specifically professional or academic as LinkedIn has. Twitter and Facebook/Meta have group segmentation capability for specific groupings or communities, as in an auxiliary ability of having another manageable account. As a LinkedIn user, however, users and other connected people represent the primary service opportunity, and all users are within an isolated, educated, professional platform.

According to Omnicore (2021, n.p.) the total population of 790 million users of the LinkedIn platform boasts over 690 million professionals as of 29 June 2021 (LinkedIn Marketing Solutions, 2021). Additionally, 80\% of LinkedIn users are executive-level professionals as stated by the same site. Females makeup $43.1 \%$ of LinkedIn users, while male users are $56.9 \%$. Written another way, 326 million female users are on LinkedIn and there are 430 million male users. Finally, 51\% of LinkedIn users self-report as having a college degree and above, and most users come from an age range of 25 - 49 (PEW, 2021, n.p.). As such, LinkedIn users, it was assumed, represented a particularly educated, somewhat ambitious, entrepreneurial population, more than adequate to gauge a survey regarding higher education. LinkedIn users are a near perfect demographic for surveys related to higher education or other academic, business, and professional topics. This is the reason LinkedIn was chosen as the platform to inform the following study.

\section{Materials and Methods}

\subsection{Survey Instrument}

The author prepared a refined survey via Surveymonkey.com which was then shared by a link to his 1760 LinkedIn connections. The survey instrument at issue here consisted of five research questions. Four of the questions were developed to invoke a 5-point Likert Scale. Each question was presented via multiple choice and required an answer before proceeding to the subsequent question. The questions were related but not entirely sequential. The fifth question simply calculated for percentage by choice and was not evaluated via Wilcoxon SignedRank test. Finally, there was a section where respondents could offer commentary.

The questions each demanded three different scales resulting in the need for four separate Wilcoxon Signed-Rank tests. These statistical tests were ran on each query. Questions 1 and 2 used the same Likert verbal interpretation. Questions 3, 4, and 5 utilized individually distinct verbal interpretations, but 3 and 4 
were weighted the same way (5-point Likert) as the other questions. The Likert scales represented interval level data (Geoff, 2010: p. 629). There was one dependent variable: LinkedIn user. The independent variables consisted of the resulting five individual responses to choice. No other demographic information was taken, or asked from the participants, per the rationale stated in the introduction.

The survey guaranteed anonymity and was administered online only via social media platform LinkedIn, having a population $(n=621)$ with immediate access to (or evidently viewed) the survey. Respondents consisted of a specialized professional, quasi-professional sample (non-normal). Non-parametric tests are perfect for data analysis satisfying those two criteria (Mircioiu \& Atkinson, 2017: p. 2). The actual number of participant respondents was $n=18$ (2.9\%) of targeted population who actually viewed/considered the survey post and call for participants (rounded to nearest tenth). LinkedIn documents and tracks views-per-post which supports accuracy of examining true response of $n$.

There was a true $2.9 \%$ response rate, which was very small. The survey was offered over a five-day period: the 5 September and 9 September 2021. Over this period the survey was posted twice, once on the fifth and the second time on the ninth of September, respectively.

The hypotheses put forth by this author were: 1) respondents will tend toward free-access to college up to the bachelor's degree; and 2) state that college is necessary; 3) worth advocating for; that 4) respondents will express support for low-interest policies needed to address broader access to a higher education; and 5) a positive respondent attitude regarding lifelong learning as a necessity. The five research questions were put forth, as follows:

RQ1: From 1 - 5 scale, how important is education after k-12? 1-Not at all important; 2-Not very important; 3-Undecided; 4-Some importance; 5Absolutely Necessary.

RQ2: On a scale of 1 to 5 , how important is education over the lifespan? 1-Not at all important 2-Not very important 3-Undecided; 4-Some importance; 5-Absolutely Necessary.

RQ3: On a scale of 1 to 5, do you advocate education for others (such as friends or children, nephews and nieces)? 1-Never; 2-Once; 3-Undecided; 4-A few times; 5-Always.

RQ4: If you could choose one of the five following solutions (for up to a bachelor's degree) related to higher education, which would it be? 1-Not change anything; 2-Offer low interest loans to students; 3-Undecided; 4-Offer lowinterest loans, plus 50\% off tuition, and; 5-Free universal education.

RQ5: If available with super low cost I would enroll in some form of higher education? 1-No, not at all; 2-Not very likely; 3-Undecided; 4-Maybe; 5Absolutely, Yes.

For RQ1 - RQ4, the null hypotheses (H0) would be true if the median responses for these RQs was $\leq 3.41$. The RQ5 is different from the other questions 
in terms of range of agreement and poll-like construction. While presented in Likert-type form it was not evaluated in the way the other questions were. The hypothesis for RQ5 was that respondents would favor answer 4, Low-interest student loans and 50\% tuition reduction over any other.

\subsection{Methodology}

Non-parametric analysis of survey questions (Likert or Likert-type data) is commonplace among researchers (Lloyd, Torelli \& Pollack, 2020: p. 441; Murray, 2013). The methodology of survey deployment is also very common in social science research (Geoff, 2010). This survey methodology has practical and rational advantages over other forms of research, such as journalism and abductive-reasoning, for example, and can lend itself also to quantitative analysis if the design survey instrument is carefully crafted (Geoff, 2010; Cooper \& Johnson, 2016). The Wilcoxon Signed-Rank test is a traditional interval-level statistical technique used for Likert data which some argue as strictly ordinal (Bishop \& Herein, 2015: p. 298; Geoff, 2010: p. 627) and the choice of analysis came down to basically parametric Analysis of Variance $(A N O V A)$, $t$-test, or the non-parametric Wilcoxon Signed-Rank Hypothesis test. Reasoning about choice of test is detailed in the discussion and limitations section.

\section{Results}

The following tables depict the results from each RQ. Overall, the results of the survey were that each null hypotheses $H_{0}$ were rejected.

\subsection{Research Question 1}

For the current RQ, (Table 1) the resulting response for RQ1 "How important is education after $\mathrm{k}-12$ ?" was that $100 \%$ of respondents agreed that education is important after high school. The true median was in range $\geq 4.21-5.00$ at 4.50 . Test result range value: 4.99 .

For Wilcoxon, subtracting $H_{0}$ median of -3.41 , from each of the 18 ranked values there was $T+=12.5$ for each " 5 " selected by the respondents, separating 12 ties in the $7-18$ ranked positions $=12(12.5)=150$. And $T-0($ or $T+=3.5)$ for each " 4 " chosen, separating 6 ties: $3.5(6)=21$. Calculating for $T=(T++T-)$

Table 1. Wilcoxon signed-rank test RQ1.

\begin{tabular}{ccccc}
\hline Scale & Range & Verbal Interpretation & Results & Median \\
\hline 1 & $1.00-1.80$ & Not at all important. & 0 & \\
2 & $1.81-2.60$ & Not very important. & 0 & \\
3 & $2.61-3.40$. & Undecided. & 0 & \\
4 & $3.41-4.20$ & Some importance & $6(33.3 \%)$ & \\
5 & $4.21-5.00$ & Absolutely Necessary. & $12(66.6 \%)$ & 4.50 \\
\hline
\end{tabular}

Source: Elton. Note: zero added to end of numbers to easily convert to \%. 
$=171.00$. The table for $T$ value was then consulted using the $T$-value of -0 . For a population of $18(n=18)$ the critical value $(T)$ is 23 and 27 with a confidence level $0.05,0.01$ respectively for a one-tailed Wilcoxon Signed-Rank test. There was sufficient robustness to establish the results were significant. Thus, provided that each of these scores at $95 \%-99 \%$ confidence levels were $0 \leq T=28$, thus rejecting the null hypothesis $\left(H_{0}\right)$ directly.

Additionally, the author calculated the $z$-score (14.12) to calculate a $p$-value. At a 0.05 confidence level for a one-tailed test if a $p$-value was $<0.05$ the results would be significant. After calculating a $p$-value of $<0.0001$, it alternatively supports the findings Wilcoxon Signed-Rank test.

\subsection{Research Question 2}

The results of RQ2 (Table 2) indicated agreement amongst respondents as $n=$ $100 \%$. The mean resulting response for RQ2 "How important is education over the lifespan?" was " 5 ", which fell between the $\geq 4.20$ - 5.00 interval. The true median was also " 5 " and the test result range value: 4.99 , therefore, the $H_{0}$ was rejected. As in the above result, RQ2 was also certain.

For Wilcoxon, subtracting -3.41 , from each of the 18 ranked values we get $T+$ $=12.5$ for each 5 chosen by the respondents, separating 15 ties in the $4-18$ ranked positions $=15(11)=165$. And $T-0($ or $T+=2)$ for each 3 chosen, separating 3 ties: $2(3)=6$. Calculating for $T=(T++T-)=171.00$. The table for $T$ value was then consulted using the $T$ - value of -0 . For a population of $18(n=$ 18 ) the critical value $(T)$ is 23 and 27 with a confidence level $0.05,0.01$ respectively for a one-tailed Wilcoxon Signed-Rank test. There was sufficient robustness to establish the results as significant. Thus, provided that each of these scores at $95 \%-99 \%$ confidence levels were $0 \leq T=28$, thus rejecting the null hypothesis $\left(H_{0}\right)$ identified by the Wilcoxon Signed-Rank test.

Additionally, the author calculated the $z$-score (13.85) to determine a $p$-value. At a 0.05 confidence level for a one-tailed test if a $p$-value was $<0.05$ the results would be significant. After calculating a $p$-value of $<0.0001$, it alternatively supports the findings Wilcoxon Signed-Rank test.

\subsection{Research Question 3}

The results of RQ3 (Table 3 ) showed agreement across respondents as $n=100 \%$.

Table 2. Wilcoxon signed-rank test RQ2.

\begin{tabular}{ccccc}
\hline Scale & Range & Verbal Interpretation & Results & Median \\
\hline 1 & $1.00-1.80$ & Not at all important & 0 & 5 \\
2 & $1.81-2.60$ & Not very important & 0 & \\
3 & $2.61-3.40$ & Undecided & 0 & \\
4 & $3.41-4.20$ & Some importance & $3(16.6 \%)$ & \\
5 & $4.21-5.00$ & Absolutely Necessary & $15(83.3 \%)$ & \\
\hline
\end{tabular}

Source: Elton (2022). Note: zero added to end of numbers to easily convert to \%. 
Table 3. Wilcoxon signed-rank test RQ3.

\begin{tabular}{ccccc}
\hline Scale & Range & Verbal Interpretation & Results & Median \\
\hline 1 & $1.00-1.80$ & Never & 0 & 4.50 \\
2 & $1.81-2.60$ & Once & 0 & \\
3 & $2.61-3.40$ & Undecided & 0 & \\
4 & $3.41-4.20$ & A Few Times & $2(11.1 \%)$ & \\
5 & $4.21-5.00$ & Always. & $16(88.8 \%)$ & \\
\hline
\end{tabular}

Source: Elton. Note: zero added to end of numbers to easily convert to $\%$.

The RQ3 was, "Do you advocate education for others (such as friends or children, nephews and nieces)?” Respondents advocated for higher education. The true median was in range $\geq 4.21-5.00$ at 4.50 . Test result range value was 4.99 , therefore the null hypothesis $\left(H_{0}\right)$ was rejected. Much of these results will be same the process for Wilcoxon Signed-Rank test. For Wilcoxon, subtracting -3.41 , from each of the 18 ranked values we get $T+=10.5$ for each 5 chosen by the respondents, separating 16 ties in the $4-18$ ranked positions $=16(10.5)=$ 168. And $T-0$ (or $T+=1.5$ ) for each 4 chosen, separating 2 ties: $2(1.5)=3$. Calculating for $T=(T++T-)=171.00$. The table for $T$ value was then consulted using the $T$ - value of -0 .

For a population of $18(n=18)$ the critical value $(T)$ is 23 and 27 with a confidence level 0.05, 0.01 respectively for a one-tailed Wilcoxon Signed-Rank test. There was sufficient robustness to establish the results were significant. Thus, provided that each of these scores at 95\% - 99\% confidence levels were $0 \leq T=$ 28 , the author was able to easily reject the null hypothesis $\left(H_{0}\right)$ directly using Wilcoxon Signed-Rank test. (The $z$-score for $p$-value will not be repeated for RQ3-4. The data is similar to the others and easily processed as in the aforementioned tables).

\subsection{Research Question 4}

The results of RQ4 (Table 4) showed agreement across respondents as $n=$ $100 \%$. RQ4 was "If you could choose one of the five following solutions (for up to a bachelor's degree) related to higher education, which would it be?" Respondents advocate at a rate of $83.3 \%$ for education. The median was " 5 ". The test value range was $4.78 \geq 3.41$ therefore the null hypothesis $\left(H_{0}\right)$ is rejected.

For Wilcoxon, subtracting -3.41 , from each of the 18 ranked values we get $T+$ $=10.5$ for each " 5 " chosen by the respondents, separating 12 ties in the $7-18$ ranked positions $=12(13)=174$. And $T-0($ or $T+=4.5)$ for each 4 chosen, separating 4 ties: $4(4.5)=18$. And $T-3.18$ (or $T-=-1.59)$ for each 2 chosen, separating 2 ties: $2(-1.59)=-3.18$. Calculating for $T=(T++T-)=170.82$. The table for $T$ value was then consulted using the $T$ - value of 3.28; however this number was not reductive of the total. This it becomes negated, effectively a 0 for statistical purposes, as in the previous tables. For a population of $18(n=18)$ 
Table 4. Wilcoxon signed-rank test RQ4.

\begin{tabular}{|c|c|c|c|c|}
\hline Scale & Range & Verbal Interpretation & Results & Median \\
\hline 1 & $1.00-1.80$ & Not change anything & 5 & \\
\hline 2 & $1.81-2.60$ & Offer low-interest loans & $2(0.11 \%)$ & \\
\hline 3 & $2.61-3.40$ & Undecided. & $1(0.05 \%)$ & \\
\hline 4 & $3.41-4.20$ & $\begin{array}{l}\text { Low-interest loans } \\
\text { Plus } 50 \% \text { off tuition }\end{array}$ & $4(22.2 \%)$ & \\
\hline 5 & $4.21-5.00$ & Free universal education & $11(61.1 \%)$ & \\
\hline
\end{tabular}

Source: Elton. Note: zero added to end of numbers to easily convert to \%.

the critical value $(T)$ is 23 and 27 with a confidence level $0.05,0.01$ respectively for a one-tailed (upper limit) Wilcoxon Signed-Rank test. There was sufficient robustness to support the results were significant. Thus, provided that each of these scores at $95 \%-99 \%$ confidence levels were $0 \leq T=28$, the null hypothesis $\left(H_{0}\right)$ was rejected via Wilcoxon Signed-Rank test calculation.

\subsection{Research Question 5}

The results of RQ5 (Table 5) "If available with super low cost I would enroll in some form of higher education?" showed the majority of respondents favored "Free universal education" at a rate of $77.7 \%$. The next meaningful option at $11.1 \%$ support an option of low-interest student loans combined with $50 \%$ off tuition rates. There were no "Undecided" of population. Option 1 and option 2 represented "Not change anything," and "Offer low-interest student loans," to which these options share $0.05 \%$ of the total respondents, respectively. An ${ }^{*}$ indicates that the respondent elected to qualify the response by explaining chose "1" due to having earned a PhD.

If the average of each of the 4 Likert questions is calculated, a sentiment score for the entire survey can be known. The sentiment score of this 4-query Likert data has an average of 4.675 with $n=18$. Next, this total gets rounded down to 4 . This means that respondents generally did not have a negative attitude toward the survey. This score contributes to truthfulness of the study and used as primary or supplemental analysis in many disciplines (Lennox, Veríssimo, Twardek, Davis, \& Jarić, 2020).

\section{Discussion and Limitations}

This examination of the LinkedIn social media demographic was a constricted non-normal specialized population. This situation, combined with low participation provided criteria for employing the Wilcoxon Signed-Rank one-tailed test as opposed to a parametric test such as $t$-test.

Demographic data was purposely left out because partly, LinkedIn users are for the most part split down the middle in both gender and college degrees. Moreover, LinkedIn provided a targeted and uniquely informed population through which to survey. 
Table 5. \% of Response on systemic changes without WilcoxonStat.

\begin{tabular}{lcc}
\hline Questions Presented & Total & Percentage \\
\hline 1. No, not at all & $1^{\star}$ & $(0.05 \%)$ \\
2. Not very likely & 1 & $(0.05 \%)$ \\
3. Undecided & 0 & \\
4. Maybe & 2 & $(11.1 \%)$ \\
5. Absolutely, Yes. & 14 & $(77.7 \%)$ \\
\hline
\end{tabular}

Source: Elton. Note: zero added to end of numbers to easily convert to $\%$.

Although the survey was restricted to one survey per device, there was no indication that anyone tried participating twice. As for the survey itself, creating a thoughtful investigatory tool to use for rapid responses certainly fits the social mood of the internet age. Society wants things fast and without delay. This seems to be true with academia as well with the advent of pre-prints and early dissemination opportunities of open-access papers.

While not a large population total for participation, there are great tools available from social media that refine ideas such as response rate. For example, LinkedIn tracks the total number of viewers of one's post which provides much more accuracy regarding true "respondents." In the days before email and internet dissemination of data and surveys, phones and letters via snail mail were heavily relied upon. With LinkedIn, while a user might have hundreds of followers (or many thousands) each post exposes the true number of actual viewers, or "respondents" in any case. This is very convenient and supportive of internal and external validity. Under the older, snail mail method, one might have had to send out 500 envelopes with 100 not being returned only because the address was wrong. The researcher would nevertheless be ethically compelled to report that extra 20\%-although not realizing it were not true addresses-were included as part of his response rate. This metric helped avoid such issues. Thus, for accuracy, the views of the post $(v=n)$ calculated as the total population reached, not the author's total connections $($ atc $\neq n$ ). As those having not seen the post were not online during the period of posting. Had all 1760 persons viewed the post, the author would have used that number. In either situation, the method of analysis would be appropriate as either directly implicates the ability to reply.

The first posting received the majority of views, whereas the second posting only received 26 views. Only two respondents came from the second posting. Thus, most any online survey will likely have data saturation within a few days after initial posting.

There has been an historic debate about whether Likert-type data is completely ordinal-level data or also somewhat interval. Regarding the literature, especially Geoff (2010) and Cooper and Johnson (2016), both of their works agree as to Likert questions as ordinal, though the distinction lies with Geoff (2010) 
who, as this author did, falls into the school of thought that Likert data can approximate interval-level data. This was the approach in this paper where each Likert item was ranged equally by 0.80 (from 1.00 - 5.00).

As to the academic debate between use of non-parametric tests versus parametric ones ( $p$-value method, $t$-test, ANOVA), the debate truly comes down to robustness as opposed to whether or not it can be done. The researchers employing Likert surveys simply must be careful in the design stage, before moving to test hypotheses. At any rate, this survey produced a robust finding. And there were no problems using Wilcoxon Signed-Rank test to evaluate Likert. The single population sample, even at 18 respondents, left no reason to doubt the general sentiments of the responses. Is it generalizable to the broader population? Maybe not, as LinkedIn represents a generally more informed microcosm, yet the general public may score similarly about these issue. More research needs to be done.

Additionally, as to the response by the $\mathrm{PhD}$; that answer was qualified by commenting that said respondent was already educated and so personally, whether low-cost or free, education opportunities did not apply to that respondent. While this may arguably be syntactical weakness of that survey question, it could be interpreted as a social question, also, and that is one of the wonders of surveys-as researchers want that honest subjectivity. On the other hand, if that reply was thrown out as an outlier, the result of the study would be the same. That is robustness. We can accept people with any level of education, including a $\mathrm{PhD}$ may be satisfied with their level-and can have a little fun with the survey-but in the end the survey provided for such accuracy in responses. Finally, the results represented an accurate attitude of LinkedIn users. The survey is easily replicated and perhaps can be redesigned, perhaps using grounded theory, for longitudinal accuracy and perspectives.

\section{Conclusion}

While indirectly expanding on potentially three-families of literature (Likert analysis, social media research, and higher education), the conclusion can be drawn that research in social media is a great area where graduate students and those entering academia can practice research. There is great potential here for the future grounded theory researcher. Also consider if there are strict rules about conducting research of one's peers in school, as one may need clearance with the IRB (internal review board); perhaps researching college students in America is still banned.

Another positive idea is that social media research is largely without such red tape and yet in its infancy, but growing (El Rassi, Elie, Bardus, Meho, \& Farha, 2017). Care must need to be taken to not expose private information or place anyone in danger. As for social media research generally, governments have long recognized its value and citizens have sometimes fought against it. Researchers in many fields have taken to social media to disseminate findings, meet collabo- 
rators, and even make decisions based on such papers and postings (Bardus et al., 2020; Sugimoto, Work, Larivière, \& Haustein, 2017). The value of social media for research is still to be fully discovered. Students should take time to explore this as an option to learn how to conduct research and use of one's field statistics.

While this LinkedIn survey does not provide the answer to eliminating discrimination of higher education, cost of education, or the logistics of incorporating free universal education, it does provide some comfort that the people who we most ascribe to being intelligent and have documented education, do care about the future of higher education and in fact realize it needs to change. One can take issue with choice of statistic, survey design, or whatever journal did or did not publish these findings, though, the bottom line is that we have a problem that most people care very much about, and over decades not many seem to truly know how to go about fixing it (Parnell, 1990). Low-interest student loans allow the financial institutions some incentive, which was why this author slightly underestimated the opinions about RQ4. Perhaps financial institutions are part of the problem. Education, along with social security, and incarceration perhaps need not be privatized nor for-profit. History has shown humans tend to cross the line, blur the lines, or bend the rules, etc when money or power is in hand. It will take a vast movement to address the economic issues facing higher education students; the time for change has been here for decades (Chamorro-Premuzic \& Frankiewicz, 2019; Parnell, 1990).

\section{Conflicts of Interest}

The author declares no conflicts of interest regarding the publication of this paper.

\section{References}

Bardus, M., El Rassi, R., Chahrour, M., Akl, E., Raslan, A., Meho, L., \& Akl, E. (2020). The Use of Social Media to Increase the Impact of Health Research: Systematic Review. Journal of Medical Internet Research, 22, e15607.

Bishop, P., \& Herron, R. (2015). Use and Misuse of the Likert Item Responses and Other Ordinal Measures. International Journal of Exercise Science, 8, 297-302. https://www.ncbi.nlm.nih.gov/pmc/articles/PMC4833473/

Cabrera, N., Franklin, J., \& Watson, J. (2016). Whiteness in Higher Education. ASHE Higher Education Report, 42, 7-125. https://doi.org/10.1002/aehe.20116

Chamorro-Premuzic, T., \& Frankiewicz, B. (2019). 6 Reasons Why Higher Education Needs to Be Disrupted. Harvard Business Review. https://hbr.org/amp/2019/11/6-reasons-why-higher-education-needs-to-be-disrupted

Cooper, D., \& Johnson, T. (2016). How to Use Survey Results. Journal of the Medical Library Association, 104, 174-177. https://doi.org/10.3163/1536-5050.104.2.016

El Rassi, R., Elie, A., Bardus, M., Meho, L., \& Farha, A. (2017). The Use of Social Media for Disseminating Health Research. University of York. http://www.crd.york.ac.uk

Geoff, N. (2010). Likert Scales, Levels of Measurement and the "Laws" of Statistics. Advances in Health Sciences Education, 15, 625-632. 
https://doi.org/10.1007/s10459-010-9222-y

Goldrick-Rab, S., Richardson, J., Schneider, J., Hernandez, A., \& Cady, C. (2018). Still Hungry and Homeless in College. Wisconsin Hope Lab. https://hope4college.com/wp-content/uploads/2018/09/Wisconsin-HOPE-Lab-Still-Hu ngry-and-Homeless.pdf

Hornsby, T. (2021). Student Loan Debt Statistics in 2021: A Look at the Numbers. Student Loan Planner. https://www.studentloanplanner.com/student-loan

Jencks, C., Riesman, D., \& Jencks, C. (2002). The Academic Revolution. Routledge.

Lennox, R. J., Veríssimo, D., Twardek, W. M., Davis, C. R., \& Jarić, I. (2020). Sentiment Analysis as a Measure of Conservation Culture in Scientific Literature. Conservation Biology, 34, 462-471. https://doi.org/10.1111/cobi.13404

LinkedIn Marketing Solutions (2021). https://business.linkedin.com/mark

Lloyd, B., Torelli, J., \& Pollack, M. (2020). Practitioner Perspectives on Hypothesis Testing Strategies in the Context of Functional Behavior Assessment. Journal of Behavioral Education, 30, 417-443. https://doi.org/10.1007/s10864-020-09384-4

Lumina Foundation (2021). https://www.luminafoundation.org/campaign/todays-student/

Mircioiu, C., \& Atkinson, J. (2017). A Comparison of Parametric and Non-Parametric Methods Applied to a Likert Scale. Pharmacy, 5, Article No. 26. https://doi.org/10.3390/pharmacy5020026

Murray, J. (2013). Likert Data: What to Use, Parametric or Non-Parametric? International Journal of Business and Social Science, 4, 258-264. https://ijbssnet.com/journals/Vol 4 No 11 September 2013/23.pdf

Omnicore Agency (2021). Linkedin by the Numbers: Stats, Demographics \& Fun Facts. https://www.omnicoreagency.com/linkedin-statistics/

Ornstein, A. (2019). Wealth, Legacy and College Admission. Society, 56, 335-339. https://doi.org/10.1007/s12115-019-00377-2

Parnell, D. (1990). Dateline 2000: The New Higher Education Agenda. American Association of Community and Junior Colleges. https://eric.ed.gov/?id=ED316270

PEW Research Center (2021). Use of Online Platforms by Demographic Groups. 7 p. https://www.pewresearch.org.pdf

Sugimoto C., Work S., Larivière V., \& Haustein, S. (2017). Scholarly Use of Social Media and Altmetrics: A Review of the Literature. Journal of the Association for Information Science and Technology, 68, 2037-2062. https://doi.org/10.1002/asi.23833

Urban Institute (2021). Working during College. http://collegeaffordability.urban.org

Vuleta, B. (2021). 37 Stunning College Student Statistics. Seed Scientific. https://seedscientific.com/college-student-statistics/

Woolston, C. (2020). White Men Still Dominate in UK Academic Science. Nature, 579, 622. https://doi.org/10.1038/d41586-020-00759-1 